\title{
COMPLIANCE E MEIO AMBIENTE: SUA IMPORTÂNCIA PARA A GESTÃO EMPRESARIAL
}

\author{
Beathrys Ricci Emerich* \\ Flavia Jeane Ferrari** \\ Sandra Mara Maciel-Lima*
}

\begin{abstract}
Resumo
O presente projeto trata da discussão sobre os programas de compliance possíveis de serem implantados na gestão empresarial para uma redução de danos causados ao meio ambiente. Objetiva investigar como os programas de compliance podem contribuir para a efetivação dos direitos e garantias fundamentais do meio ambiente empresarial em âmbito geral. $\mathrm{O}$ tipo de pesquisa visa proporcionar maior familiaridade com um problema em razão de escolhermos para procedimentos técnicos de investigação o levantamento bibliográfico, elaborada a partir de consultas acerca do entendimento de constitucionalistas e juristas e empreendedores sobre a aplicabilidade do compliance na gestão empresarial.
\end{abstract}

Palavras-chave: Compliance; Ecoeficiência Empresarial; Soluções Sustentáveis; Práticas de Gestão Ambiental; Danos Ambientais.

\section{ENVIRONMENTAL COMPLIANCE: ITS IMPORTANCE FOR BUSINESS MANAGEMENT}

\begin{abstract}
The project refers to the discussion about compliance projects which can be implemented in business management to decrease environmental impact. Aims to investigate how compliance programs can contribute to both fundamental and general environmental rights. This is an expanded research that aims to increase familiarity with a new problem. For this reason, we choose as survey procedure a bibliographical research. This bibliographical survey will be elaborated from consultations about the understanding of constitutionalists, jurists and entrepreneurs on the applicability of compliance in business management. The bibliographical survey will also use academic articles on appropriate websites.
\end{abstract}

Keywords: Compliance; Business Eco-Efficiency; Sustainable Solutions; Best Practices in Environmental Management; Environmental Damage

\section{INTRODUÇÃO}

\footnotetext{
*Advogada e Mestranda em Direito no Programa de Pós-Graduação em Direito Empresarial e Cidadania do Unicuritiba. Endereço eletrônico: ricciemerich.adv@gmail.com

*** Advogada e Mestranda em Direito no Programa de Pós-Graduação em Direito Empresarial e Cidadania do Unicuritiba. Endereço eletrônico: flaviajeane.ferrari@ hotmail.com

*** Professora e Pesquisadora do Programa de Pós-Graduação em Direito Empresarial e Cidadania do Unicuritiba. Endereço eletrônico: maciellima.sandra@gmail.com; sandra.mara@ unicuritiba.com.br
} 
O presente trabalho tem o objetivo de abordar a importância de um programa de compliance dentro das práticas corporativas, de modo que seus dirigentes adequem suas práticas e não sejam surpreendidos com responsabilização civil, administrativo e criminal por eventuais danos causados ao meio ambiente em razão das atividades da empresa.

Nesse cenário, empresas com mais de uma década de existência podem facilmente afirmar que as questões sobre a legislação ambiental, bem como a fiscalização, nem sempre foram preocupações. Todavia, o dever de estar em conformidade com a legislação, em especial as que regulam a preservação do meio ambiente, é um tema cada vez mais presente nos programas das empresas atualmente.

É de suma importância investigar “posição atual das pessoas jurídicas e seus mecanismos de controle, prevenção e reparação dos danos causados ao meio ambiente em decorrência de suas atividades", assim como, "o despertar social para o denominado consumo sustentável, que parece impulsionar tantas pessoas como empresas na busca por condutas preservadoras do meio ambiente". (JECKEL, 2012, n.p.)

Dentre os objetivos específicos, a pesquisa visa definir o termo compliance, compreender a aplicabilidade do compliance nas organizações, em caráter preventivo, diante dos desafios no meio ambiente; identificar os objetivos do compliance ambiental; e, por fim, exemplificar o compliance ambiental nos setores financeiros, a título de novo paradigma no setor financeiro.

O estudo vem sendo realizado mediante abordagem qualitativa, utilizando-se de pesquisa bibliográfica e documental, assim como, de análises de doutrinas, artigos e legislações.

Pretende-se, portanto, esclarecer a seguinte pergunta: as empresas estão adotando práticas de gestão ambiental, como programas de compliance, que estimulem resultados ecoeficientes?

Assim, na primeira parte deste artigo, será necessário definir o termo compliance, compreender a aplicabilidade do compliance nas organizações, em caráter preventivo, diante dos desafios no meio ambiente; identificar os objetivos do compliance ambiental; e, por fim, exemplificar o compliance ambiental nos setores financeiros, a título de novo paradigma no setor financeiro.

O presente estudo entende o compliance como um aliado das empresas na gestão empresarial e um importante instrumento para a gestão ambiental e social. Pretente, também, 
contribuir para o entendimento dos avanços conquistados na perspectiva das políticas públicas, no que diz respeito às questões de preservação do meio ambiete.

Por fim, destaca-se a compelxidade e relevância da questão estudada neste artigo, não sendo objetivo aqui esgotar o assunto, mas apenas trazer alguns apontamentos importantes acerca do compliance e dos direitos fundamentais do meio ambiente no âmbito empresarial.

\section{DEFINIÇÃO DO TERMO COMPLIANCE}

O termo compliance tem origem da língua inglesa (do verbo to comply) e, significa cumprir, satisfazer alguma regra (BITTENCOURT, 2015), sendo adotada no campo empresarial como:

[...] um conjunto de medidas internas que permite prevenir ou minimizar os riscos de violação às leis decorrentes de atividade praticada por um agente econômico e de qualquer um de seus sócios ou colaboradores. Por meio dos programas de compliance, os agentes reforçam seu compromisso com os valores e objetivos ali explicitados, primordialmente com o cumprimento da legislação. Esse objetivo é bastante ambicioso e por isso mesmo ele requer não apenas a elaboração de uma série de procedimentos, mas também (e principalmente) uma mudança na cultura corporativa. O programa de compliance terá resultados positivos quando conseguir incutir nos colaboradores a importância em fazer a coisa certa. (CARVALHO, 2016, p. 09)

Uma definição do instrumento de conformidade advinda do CADE é a de que: "compliance é um conjunto de medidas internas que permite prevenir ou minimizar os riscos de violação às leis decorrentes de atividade praticada por um agente econômico e de qualquer um de seus sócios ou colaboradores" (CADE, 2018, p. 09).

O compliance é uma criação norte-americana que emergiu na década de 60 com o intento de formar estratégias próprias e específicas de controle, treinamento de pessoal e inspeção, com a finalidade de auxiliar a governança e outras áreas de negócios na obtenção efetiva de supervisão.

Esse conceito de compliance "foi implementado após o período pós-Revolução Industrial, oriundo do processo de crescimento populacional que gerou um aumento na 
demanda e, consequentemente a possibilidade de crescimento da oferta, gerando um modelo de produção em série que deu ensejo à diminuição dos custos, atingindo maior número de pessoas" (NUNES, 2009, p. 3).

“O compliance teve seu surgimento no Brasil na década de 90, quando o País abriu o mercado nacional na tentativa de alinhamento com o cenário internacional". Cenário este, que “já estava se adequando com a fiscalização e transparência no conceito normativo, principalmente no setor econômico, quando da crise bancária americana" na década de 30 . (GOMES; OLIVEIRA, 2017, p. 190)

Desde que a área ambiental vem ganhando importância na sociedade, sobretudo relacionada às relações de consumo, um número crescente de empresas vem se preocupando com suas próprias posturas num tripé formado pelas dimensões social, econômica e ambiental (BARBIERI, 2010), cuja acentuação encontra eco na premissa "pensar global, agir local", no diapasão da denominada Agenda 21 (BRASIL, 1995).

\subsection{ATUAÇÃO DO COMPLIANCE}

Na visão de Candeloro, Rizzo e Pinho (2012), o compliance tem como finalidade garantir a confidencialidade das informações prestadas pelos clientes das empresas; evitar conflito de interesses entre os diversos atores da instituição; evitar ganhos individuais por meios artificiais de mercado, ou uso informações privilegiadas; e, finalmente, disseminar, dentro da cultura organizacional, por meio de educação e treinamento, os valores de compliance.

Sob a ótica de Blok (2017), a importância do compliance no cenário brasileiro tem o foco principal nas instituições bancárias, principalmente nas áreas voltadas a combater possíveis fraudes. O Bacen determinou 37 normas com o cunho de assegurar o capital de terceiros assim como evitar práticas de fraudes e o aproveitamento de informações privilegiadas. Assim, no cenário brasileiro a função principal do compliance é de "[...] integrar as atividades do "compliance" com as boas práticas de governança corporativa e de gestão de riscos [...]” (BLOK, 2017, p.228).

Na visão de Dalla Porta (2011, p. 12-88), o mecanismo de compliance tem a função 
de organizar as informações em meios adequados e eficientes de comunicação para facilitar o acesso de colaboradores a informações pertencentes a instituição. Além disso, tem o objetivo de tornar os membros envolvidos com a pessoa jurídica em que estão inseridos.

\subsection{IMPLANTAÇÃO DO PROGRAMA DE COMPLIANCE PELAS EMPRESAS}

A adoção de programas de compliance pelas empresas mitiga os riscos de violações da lei e suas consequências adversas.

No direito concorrencial, além de multa, a LDC prevê diversas outras penas em caso de infração à ordem econômica, como publicação da decisão condenatória em jornal de grande circulação, proibição de contratar com instituições financeiras oficiais e participar de licitação por até cinco anos, inscrição do infrator no Cadastro Nacional de Defesa do Consumidor", dentre outros. (CADE, 2018, p. 11)

Além disso, o CADE (2018, p. 12) sugere que inserir um programa de compliance em uma empresa permite aos funcionários identificar sinais de que outras empresas possam estar infringindo a lei, permitindo, assim, um melhor relacionamento da empresa no mercado.

Para Manzi (2008, p. 15),

o programa de Compliance, nada mais é do que um programa implantado pela própria empresa, que visa garantir a conformidade de suas condutas às exigências de determinada jurisdição, executando regulamentos internos e externos, impostos às atividades da instituição, buscando mitigar o risco atrelado à reputação e ao regulatório/legal.

Assim, por meio do Conceito da Culpabilidade Construtiva, do Programa de Compliance e da figura do Compliance Officer, estuda-se a possibilidade de responsabilizar a pessoa jurídica, mitigando os riscos atrelados aos crimes ambientais (LINHARES; OLIVEIRA, 2015, p. 44)

Por fim, a inserção de um programa de compliance evita que a empresa incorra em custos e contingências com investigações, publicidade negativa, interrupção das atividades, 
multas, indenizações, impedimento de participação em licitações públicas, dentre outros. (CADE, 2018, p. 13) 


\section{COMPLIANCE AMBIENTAL}

\subsection{A IMPORTÂNCIA DO PROGRAMA DE COMPLIANCE AMBIENTAL NAS EMPRESAS}

Hoffrén e Apajalahti (2009) afirmam que a ideia de ecoeficiência emergiu de vários estudos que demonstraram que o consumo de materiais estava excedendo o reabastecimento e superando a capacidade do meio ambiente, particularmente em países industrializados (HOFFRÉN; APAJALAHTI, 2009, p. 233-243)

A matéria relativa à responsabilidade ambiental tem status constitucional, e possui previsão no parágrafo $3^{\circ}$, do art. 225, da Constituição Federal do Brasil de 1988: "as condutas e atividades consideradas lesivas ao meio ambiente sujeitarão os infratores, pessoas físicas ou jurídicas, a sanções penais e administrativas, independentemente da obrigação de reparar os danos" (BRASIL, 1988, n.p.).

Ainda, no tocante ao meio ambiente, importa, aliás, o grifo em relação à Constituição Federal, que dispõe o seguinte:

\footnotetext{
Art. 170. A ordem econômica, fundada na valorização do trabalho humano e na livre iniciativa, tem por fim assegurar a todos existência digna, conforme os ditames da justiça social, observados os seguintes princípios: $[\ldots]$ VI defesa do meio ambiente; (BRASIL, 1988, n.p.)
}

A Lei dos Crimes Ambientais n 9.605/1998 “discorre sobre as sanções penais e administrativas derivadas de condutas e atividades lesivas ao meio ambiente dentre outras providências que fazem alusão ao tema em questão" (BRASIL, 1988, n.p.). A lei prevê em seu texto que a reparação do dano causado ao meio ambiente e a recuperação do ambiente natural pode eximir a pena de punição na forma de multas monetárias, e as penas de prisão no período inferior a quatro anos podem ser substituídas por penas alternativas seguidas de multa como, por exemplo, a obrigatoriedade da realização de trabalhos de auxílio à comunidade. (BRASIL, 1998).

A lei de Crimes Ambientais, é, em sua grande parte, regulada pelo procedimento 
comum sumaríssimo, Lei n. 9.099/95 de modo que a quantidade máxima da pena em abstrato é de 2 (dois) anos, isto é, de acordo com a Constituição Federal os crimes previstos na lei dos crimes ambientais são considerados infrações de menor potencial ofensivo.

Outrossim, "o cometimento de uma infração ambiental pode impedir a continuidade de uma atividade ou de um projeto, baseados na expectativa de um retorno financeiro que poderá sofrer um atraso fatal à operação. E, não se trata apenas de pagar a multa e continuar trabalhando, como se fosse um débito fiscal" (SENISE, 2014, n.p.).

Nesse sentido, “o infrator estará obrigado, ainda, à reparação do dano, pela recuperação ou indenização da área degradada, e estará sujeito, também, a responder processo por crime ambiental" (SENISE, 2014, n.p.).

Assim sendo, a função de compliance é "garantir a conformidade com as normas e verificar, em havendo eventuais situações de risco, quem seriam os responsáveis por cada ato praticado na cadeia de eventos de um empreendimento ou atividade empresarial e, quem é o responsável por fiscalizar as atividades de cada empresa” (RUOTOLO, 2017,n.p.)

O programa de compliance ambiental atua como o responsável pela identificação dos pontos vulneráveis da empresa no âmbito de sua área de atuação. Dessa forma, pode-se dizer que umas das maiores vantagens de se estabelecer um programa de compliance dentro de uma empresa consiste na antecipação a eventuais irregularidades e, por conseguinte, em evitar danos ao meio ambiente e problemas com órgãos fiscalizadores de proteção ambiental.

Além disso, a Constituição Federal trata, em seu art. 225, § $1^{\circ}$ inciso IV, que é incumbido ao Poder Público "exigir, na forma da lei, para instalação de obra ou atividade potencialmente causadora de significativa degradação do meio ambiente, estudo prévio de impacto ambiental, a que se dará publicidade” (BRASIL, 1988, n.p.)

Sendo assim, verifica-se que "os estudos de impactos ambientais podem ser constituídos de diversos instrumentos de gestão ambiental, incluindo avaliação de riscos, auditorias ambientais, avaliação de desempenho ambiental, entre outros”. (BARBIERI, 2007)

Para Pacheco (2013, n.p.), “o compliance na gestão ambiental das empresas é também um importante instrumento de adequação em uma nova era da competitividade, diante de um mercado cada vez mais acirrado e exigente".

A ISO 14001 foi atualizada em 2015, e define a estrutura, critérios e elementos para a implantação de um Sistema de Gestão Ambiental na esfera ambiental. O Sistema de Gestão Ambiental é: 
[...] uma estrutura desenvolvida para auxiliar as organizações, independentemente de seu tipo ou porte, a planejar consistentemente ações, prevenir e controlar impactos significativos sobre o meio ambiente, gerenciar riscos e melhorar continuamente o desempenho ambiental e a produtividade. Além destes aspectos, um SGA permite avaliar e monitorar a conformidade em relação ao atendimento dos requisitos legais. (LOURENÇO, 2015, p. 01)

A Lei de Crimes Ambientais, por sua vez, contempla a responsabilização penal do agente que provocou o dano, de forma dolosa ou culposa. Seu artigo $2^{\circ}$ aduz que podem ser punidos o "diretor, o administrador, o membro de conselho e de órgão técnico, o auditor, o gerente, o preposto ou mandatário de pessoa jurídica, que, sabendo da conduta criminosa de outrem, deixar de impedir a sua prática, quando podia agir para evitá-la” (BRASIL, 1998, n.p.).

\subsection{COMPLIANCE NO SETOR FINANCEIRO}

Seu marco inicial se deu em meados da década de 30, e deu origem à fundação do Bank for International Settlements (BIS), sediado na Suíça, a instituição de programas de compliance teve objetivo principal implantar a cooperação entre os bancos centrais, a fim de se combater crimes associados à chamada "lavagem de dinheiro" (ABBI; FEBRABAN, 2009).

Com as mudanças e transformações que vem ocorrendo com a modernidade, as instituições bancárias e corporativas necessitam uma maior fiscalização e prevenção (RIOS; ANTONIETTO, 2015).

Nos termos da Lei n. 6.938/1981, em seu artigo 129, que estabeleceu a política nacional do meio ambiente, as instituições financeiras, sendo eles públicos ou privados, tinham a obrigatoriedade de exigirem licenciamento ambiental para os projetos a serem financiados (BRASIL, 1981).

Em seguida surgiu o Protocolo Verde que trouxe uma nova visão da proteção ambiental no Brasil, uma vez que estes apenas não só fiscalizavam o atendimento das instituições bancárias privadas no cumprimento da legislação ambiental, mas também passaram a cobrar dos financiamentos feitos no âmbito de sua gestão. Nas palavras de Braga (2014, p. 4): 
Esse documento foi uma iniciativa pioneira na América Latina. Por meio dele, o governo promovia uma alteração em suas atribuições, uma vez que o Estado ampliava o seu papel na área ambiental, passando de órgão que apenas regulamentava e fiscalizava para promover e garantir o desenvolvimento sustentável.

A Associação Brasileira dos Bancos e pela Federação Brasileira de Bancos elaborou as finalidades de função do "compliance".

Dentre suas atribuições estão a de certificar-se do seu cumprimento; assegurar-se de sua existência, observância e implementação; assegurar-se da existência de Procedimentos associados aos Processos; assegurar-se da adequada implementação da Segregação de Funções nas atividades da Instituição, a fim de evitar o conflito de interesses; fomentar a cultura de Prevenção à Lavagem de Dinheiro, através de treinamentos específicos; e, elaborar ou certificar-se da elaboração do referido relatório com base nas informações obtidas junto às diversas áreas da instituição. (JECKEL, 2012, n.p.)

No Brasil, o "compliance" nas instituições financeiras em âmbito do meio ambiente vem se consolidando por intermédio de princípios éticos e em decorrência, também, da própria legislação pátria.

Diversas são as leis que regem as instituições financeiras e delimitam atividades que causam danos ao meio ambiente, inclusive as entidades e órgãos de financiamento e incentivos governamentais, por força da Lei $n^{\circ}$ 6.938/1981 (Política Nacional do Meio ambiente), da Lei $n^{\circ}$ 9.605/1998 (Lei de Crimes Ambientais), e da Lei no 11.105/2005 (Lei de Biossegurança), eis que,

[...] para o fim de apuração do nexo de causalidade no dano ambiental, equiparam- se quem faz, quem não faz quando deveria fazer, quem deixa fazer, quem não se importa que façam, quem financia para que façam, e quem se beneficia quando outros fazem. [...] (Recurso Especial $\mathrm{n}^{\circ}$ 650.728/SC, Rel. Min. Herman Benjamin, STJ, julgamento em 02/12/2009).

Nessa esteira, esses "controles internos pretendem prevenir a responsabilidade penal, todavia, sua concretização cria condições para que dentro da empresa se forme uma cadeia de 
responsabilização penal" (SAAVEDRA, 2011).

\subsection{A RESPONSABILIDADE PENAL DA PESSOA JURÍDICA NOS CRIMES AMBIENTAIS}

A Lei dos Crimes Ambientais (Lei $n^{\circ}$ 9.605/98), responsabiliza penalmente a pessoa jurídica nos casos de danos ambientais, tendo em vista a relevância e a gravidade da lesão, senão vejamos:

Art. $3^{\circ}$ As pessoas jurídicas serão responsabilizadas administrativa, civil e penalmente conforme o disposto nesta Lei, nos casos em que a infração seja cometida por decisão de seu representante legal ou contratual, ou de seu órgão colegiado, no interesse ou benefício da sua entidade. Parágrafo único: A responsabilidade das pessoas jurídicas não exclui a das pessoas físicas, autoras, co-autoras ou partícipes do mesmo fato. (BRASIL, 1998)

Assim, é necessário compreender que são as pessoas que “orquestram a funcionalidade de uma empresa, não havendo como não conectar as pessoas físicas a uma pessoa jurídica" (LINHARES; OLIVEIRA, 2015, p. 50).

Por outro lado, Ferreira (2009, p. 55-75) destaca que:

Tudo quanto se disse pode e deve ser aplicado para fins de apuração das infrações ambientais supostamente praticadas por pessoas físicas ou jurídicas por violação à Lei $n^{\circ} 9.605 / 98$ - que dispõe sobre as sanções penais e administrativas derivadas de condutas e atividades lesivas ao meio ambiente.

A Lei dos crimes ambientais trouxe os requisitos para a responsabilização, sendo eles, por decisão de seu representante legal ou por decisão contratual; por decisão de órgão colegiado e, por fim, que o ato seja praticado no interesse ou benefício da pessoa jurídica (BRASIL, 1998).

\section{CONSIDERAÇÕES FINAIS}


Este trabalho teve como objetivo investigar como os programas de compliance podem contribuir para a efetivação dos direitos e garantias fundamentais do meio ambiente empresarial em âmbito geral, de maneira a buscar esclarecer como o compliance pode contribuir para uma crescente conscientização em preservar o meio ambiente e minimizar os impactos das ações humanas na natureza, fazendo com que as empresas passem a agir em conformidade com o disposto no texto legal.

Assim, conforme visto no decorrer deste trabalho, um programa de compliance possibilita que a empresa evidencie e avalie os riscos, antecipando assim eventuais irregularidades que determinada atividade poderá gerar, além de evitar que essa irregularidades apareçam. Nesse sentido, a adesão por todos os indivíduos às práticas de conformidade ambiental é a principal meta a ser implantada pelas lideranças da empresa, sob pena do programa se tornar obsoleto.

Se, por um lado, o compliance é decorrente da consolidação de uma cultura ética, por outro, é produto da própria evolução da legislação pátria. Já, especificamente no tocante ao compliance ambiental, este consiste tanto no resultado dos princípios norteadores daquilo que se conhece por desenvolvimento sustentável como uma imposição de uma ordem normativa que atribui aos responsáveis diretos ou indiretos por danos causados ao meio ambiente, por esse motivo a extrema importância do estudo e aplicação do compliance ambiental na gestão empresarial. 


\section{REFERÊNCIAS}

ASSOCIAÇÃO BRASILEIRA DAS ENTIDADES DOS MERCADOS FINANCEIRO E DE CAPITAIS (ANBIMA). Basiléia III: novos desafios para adequação da regulação bancária. ANBIMA, Rio de Janeiro, 2010, p. 03. Disponível em: https://www.anbima.com.br/pt_br/informar/regulacao/perspectivas-anbima/basileia-iiinovos-desafios-para-a-adequacao-da-regulacao-bancaria.htm Acesso em: 20 jan. 2020.

ASSOCIAÇÃO BRASILEIRA DE BANCOS INTERNACIONAIS (ABBI); FEDERAÇÃO BRASILEIRA DE BANCOS (FEBRABAN). Função de “compliance”, 2009. Disponível em: https://www.febraban.org.br/7rof7swg6qmyvwjcfwf7i0asdf9jyv/sitefebraban/funcoescomplia nce.pdf Acesso em: 28 jan. 2020.

BARBIERI, J. C. Gestão ambiental empresarial: conceitos, modelos e instrumentos. 2. ed. São Paulo: Saraiva, 2007.

BARBIERI, José Carlos. Inovação e sustentabilidade: novos modelos e proposições. São Paulo, p. 146-154, 2010. Disponível em: https://www.scielo.br/pdf/rae/v50n2/02.pdf Acesso em: 20 jan. 2020.

BITTENCOURT, Sidney. Comentários à lei anticorrupção: Lei no 12.848/2013. 2. ed. São Paulo: Revista dos Tribunais, 2015.

BLOK, Marcella. Compliance e Governança Corporativa: atualizado de acordo com a Lei Anticorrupção (Lei 12.846) e Decreto-Lei 8.421/2015. Rio de Janeiro: Freitas Bastos, 2017.

BRAGA, Cláudia Oliveira da Silva. Protocolo Verde: as instituições financeiras e a promoção da sustentabilidade ambiental no Brasil, 2014, p. 04. Dissertação (Mestrado em Gestão Pública) - Universidade Federal de Pernambuco, Centro de Ciências Sociais Aplicadas, Recife.

Disponível em:

https://repositorio.ufpe.br/bitstream/123456789/11722/1/DISSERTA\%c3\%87\%c3\%830\%20 Cl\%c3\%aludia\%20Oliveira\%20Braga.pdf Acesso em: 02 dez. 2019. 
BRASIL. Conferência das Nações Unidas sobre o meio ambiente e o desenvolvimento.

Brasília, DF: Câmara dos Deputados; Coordenação de Publicações, 1995.

BRASIL. Constituição (1988). Constituição da República Federativa do Brasil. Brasília, DF: Senado Federal: Centro Gráfico, 1988. Disponível em:

https://www.senado.leg.br/atividade/const/con1988/CON1988_05.10.1988/CON1988.asp Acesso em: 02 dez. 2019.

BRASIL. Lei $\mathbf{n}^{\circ}$ 6.938, de 31 ago. 1981. Dispõe sobre a Política Nacional do Meio Ambiente, seus fins e mecanismos de formulação e aplicação, e dá outras providências. Diário Oficial, Brasília, 02 set. 1981. Disponível em: http://www.planalto.gov.br/ccivil_03/LEIS/L6938.htm. Acesso em: 27 jan. 2020.

BRASIL. Lei $\mathbf{n}^{\mathbf{0}}$ 9.605, de 12 de fevereiro de 1998. Dispõe sobre as sanções penais e administrativas derivadas de condutas e atividades lesivas ao meio ambiente, e dá outras providências. Diário Oficial, Brasília, 12 de fevereiro de 1998. Disponível em: http://www.planalto.gov.br/ccivil_03/leis/19605.htm Acesso em: 28 jan. 2020.

BRASIL. Superior Tribunal de Justiça - STJ - REsp: 650728 SC 2003/0221786-0, Relator: Ministro HERMAN BENJAMIN, Data de Julgamento: 23/10/2007, T2 - SEGUNDA TURMA, Data de Publicação: DJe 02/12/2009. Disponível em:

https://scon.stj.jus.br/SCON/jurisprudencia/toc.jsp?i=1\&b=ACOR\&livre=((\%27RESP\%27.cl ap.+e+@num=\%27650728\%27)+ou+(\%27RESP\%27+adj+\%27650728\%27.suce.))\&thesauru s=JURIDICO\&fr=veja Acesso em: 29 jan. 2020.

CADE. Conselho Administrativo de Defesa Econômica. Guia para programas de compliance. 2018, p. 09. Disponível em: http://www.cade.gov.br/acesso-ainformacao/publicacoes-institucionais/guias_do_Cade/guia-compliance-versao-oficial.pdf Acesso em: 28 jan. 2020.

CANDELORO, Ana Paula P.; RIZZO, Maria Balbina Martins de; PINHO, Vinícius. Compliance $\mathbf{3 6 0}^{\circ}$ : riscos, estratégias, conflitos e vaidades no mundo corporativo. São Paulo: 
Trevisan, 2012.

CARVALHO, Vinicius Marques de; RODRIGUES, Eduardo Frade (Coord.). Guia para programas de compliance. Brasília, DF: Ministério da Justiça; Conselho Administrativo de Defesa Econômica (CADE), jan. 2016. Disponível em http://www.cade.gov.br/acesso-ainformacao/publicacoes-institucionais/guias_do_Cade/guia-compliance-versao-oficial.pdf Acesso em 27 jan. 2020.

DALLA PORTA, Flaviano. As diferenças entre auditoria interna e compliance. Monografia (Pós-graduação em Economia). Universidade Federal do Rio Grande do Sul, Porto Alegre, 2011. Disponivel em: https://lume.ufrgs.br/handle/10183/35445 Acesso em 27 jan. 2020.

FERREIRA, Daniel. Alternativas legais à sanção administrativo-ambiental: uma eventual questão de dignidade da pessoa humana e de sustentabilidade da atividade empresarial. Revista Jurídica UNICURITIBA. Curitiba, v.2, n. 6, 2009, p 55-75. Disponível em: http://revista.unicuritiba.edu.br/index.php/RevJur/article/view/99 Acesso em: 04 fev. 2020.

GOMES, Magno Federici; OLIVEIRA, Warley Ribeiro. A efetivação do compliance ambiental diante da motivação das certificações brasileiras. RDFG - Revista de Direito da Faculdade Guanambi v. 4, n. 1, janeiro-junho 2017. Disponível em: http://revistas.faculdadeguanambi.edu.br/index.php/Revistadedireito/issue/view/8/13 Acesso em 28 jan. 2020.

HOFFRÉN, J.; APAJALAHTI, E. L. Emergent ecoefficiency paradigm in corporate environment management. Sustainable Development, 2009.

JECKEL, Michelle, Sanches B. Compliance ambiental. Jus.com.br. 2012. Disponível em: https://jus.com.br/artigos/22868/compliance-ambiental Acesso em: 04 fev. 2020

LINHARES, Sólon Cicero; OLIVEIRA, Daniele Aparecida de. O conceito construtivista de culpabilidade e a responsabilidade penal das pessoas jurídicas por crimes ambientais. Uma análise através da figura do compliance. Revista Jurídica - FURB, v. 19, n. 40, p. 41 - 60, set./dez. 2015. Disponível em: https://proxy.furb.br/ojs/index.php/juridica/article/view/4960 
Acesso em: 04 fev. 2020

LOURENÇO, Cristiane Botelho. Nova Versão da Norma ISSO 14001:2015 - O que muda?, 2015. Disponível em: http://www.ambito.com.br/index.php/blog/nova-versaoda-\%20normaiso-140012015-o-que-muda/ Acesso em: 24 jan. 2020.

MANZI, Vanessa Alessi. Compliance no Brasil: Consolidação e Perspectivas. São Paulo: Saint Paul Editora, 2008.

NUNES, Rizzatto. Curso de direito do consumidor. 4. ed. São Paulo: Saraiva, 2009.

PACHECO, Cristiano. Compliance Ambiental: Antecipe o problema. Voto Política e Negócios. 05/11/2013 Disponível em: http://cristianopacheco.com/wpcontent/uploads/2013/11/Artigo-Compliance-Ambiental-18.11.2013.pdf Acesso em: 04 fev. 2020

RIOS, Rodrigo; ANTONIETTO, Caio. Prevenção e minimização de riscos na gestão da atividade empresarial. São Paulo. Revista Brasileira de Ciências Criminais, v.23, n. 114, 2015. Disponível em: https://dialnet.unirioja.es/servlet/articulo?codigo=5165110 Acesso em: 04 fev. 2020

RUOTOLO, Caio Cesar Braga. A importância de compliance ambiental na empresa. Roncarati Editora. 04/12/2017. Disponível em: https://www.editoraroncarati.com.br/v2/Artigos-e-Noticias/Artigos-e-Noticias/A-importanciade-compliance-ambiental-na-empresa.htmlle Acesso em: 04 fev. 2020

SAAVEDRA, Giovani A. Reflexões iniciais sobre criminal compliance. In: Boletim IBCCRIM, ano 18, n. 218, 2011. Disponível em: http://espacocriminologico.blogspot.com/2011/01/reflexoes-iniciais-sobre-criminal.html Acesso em: 04 fev. 2020C

SENISE, Walter José. Lei anticorrupção é alerta para adoação do compliance ambiental. Boletim CONJUR, 31/03/2014. Disponível em: https://www.conjur.com.br/2014-mar- 
31/walter-senise-lei-anticorrupcao-alerta-adocao-compliance-ambiental Acesso em 04 fev. 2020 